\title{
Outsourcing of dentist support services was 'shambles' say MPs
}

Patients were potentially put at risk of harm and hundreds of dentists prevented from working as a result of NHS England's decision to outsource support services in primary care, according to MPs.

The decision by NHS England in 2015 to outsource primary care support services to Capita Business Services Ltd (Capita) was a 'shambles' said MPs on the Parliamentary Public Accounts Committee in a recently published report.

Primary care support services provide a range of administrative and back-office functions to dentists, GPs, opticians and pharmacists and include:

- Administering confirmation that dentists, GPs and opticians in the NHS are suitably qualified

- Processing patient registrations and de-registrations

- Administering payments to GP practices, opticians and pharmacies.

In the report Supporting Primary Care Services: NHS England's contract with Capita ${ }^{1}$, published on 25 July 2018, the Committee's MPs said there had been a short-sighted rosh to cut by a third the $£ 90$ million it cost to provide these services, regardless of the impact it would have on the 39,000 dentists, GPs, opticians and pharmacists affected.

In August 2015, NHS England entered into a seven-year, $£ 330$ million contract with Capita to deliver primary care

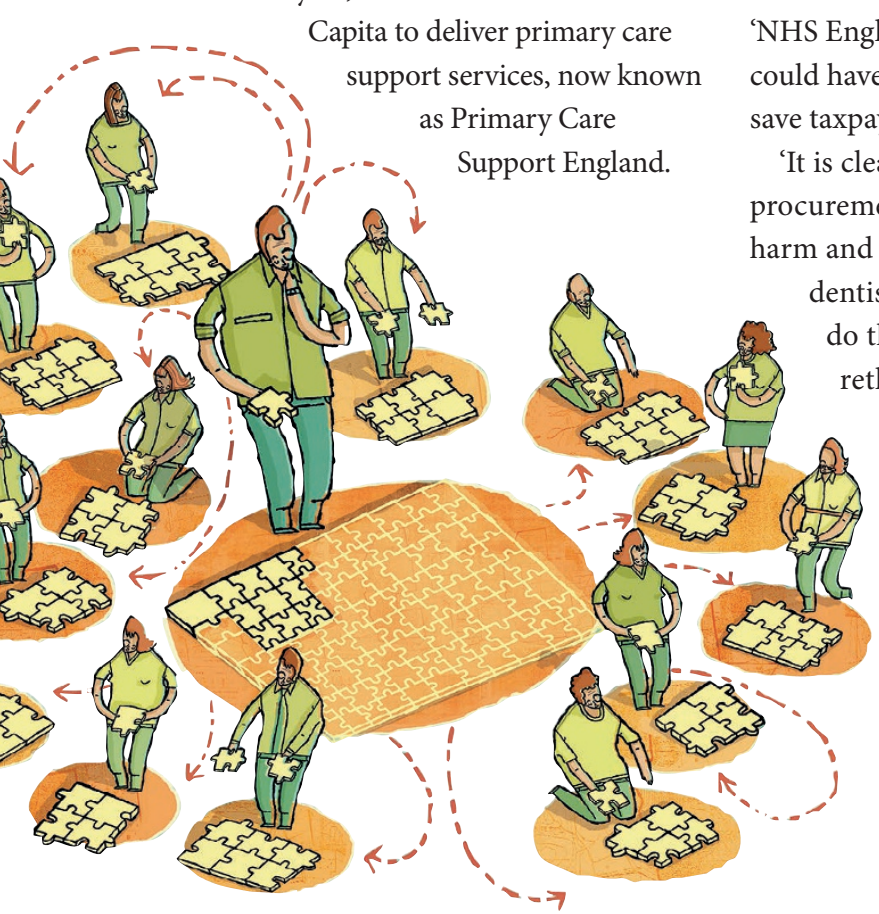

NHS England aimed to reduce its costs by $35 \%$ from the first year of the contract and create better quality support services that were more efficient and easier to use.

The new report includes details of some of the failures to deliver services that led to disruptions and extra costs for dentists, doctors, opticians and pharmacists.

One such failure to deliver back-office functions resulted in approximately 1,000 GPs, dentists and opticians being delayed from working with patients, and some lost earnings as a result.

The failure to update performers lists (confirmation that practitioners are still suitably qualified to practice) also potentially compromised patient safety in cases where practitioners should have been removed.

Stakeholders also raised concerns about missed and inaccurate payments to practitioners, a backlog of half a million patient registration letters and failures to deliver medical supplies.

The committee's MPs have recommended that NHS England should write to them by January 2019 setting out what they have done to compensate primary care practitioners for the disruption.

Neither NHS England nor Capita understood the service that was being outsourced, and both misjudged the scale and nature of the risks, said the report authors.

Committee Chair Meg Hillier MP, said: NHS England made a complete mess of what could have been a responsible measure to ave taxpayers' money.

'It is clearly unacceptable that poor procurement should put patients at risk of $m$ and undermine the ability of GPs, dentists, opticians and pharmacists to do their jobs. NHS England needs to rethink its approach to outsourcing and invest time in getting its contracts right.'

The BDA said that it had told MPs in its written evidence to the Committee that the NHS England-Capita 'fiasco' had forced hundreds of NHS dentists to stand idle for up to a year while patients were struggling to access NHS dentistry.

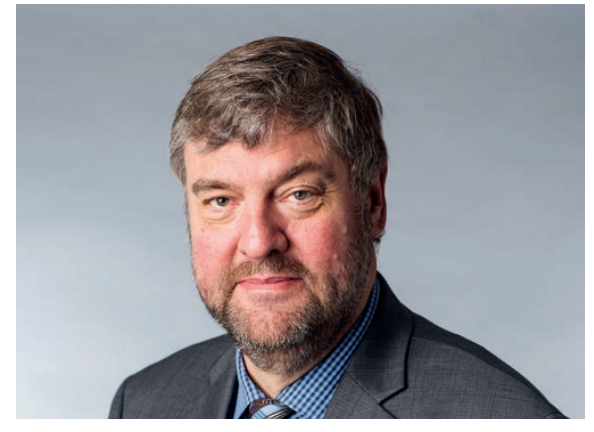

Henrik Overgaard-Nielsen, BDA Chair of General Dental Practice

The unacceptably long delays in processing NHS performer numbers (required before commencing NHS work), MPs were told, prevented NHS dentists from earning a living.

Henrik Overgaard-Nielsen, BDA Chair of General Dental Practice, said: 'We thank the MPs on the committee for listening to dentists' concerns and for making NHS England take responsibility for its grotesque failure to manage the contract.

'Given the well documented failures of NHS England to manage this contract, we have pointed out the irony to head of NHS England, Simon Stevens, that if a dentist repeatedly failed to deliver on a contract, they would be served breach notices and their contract terminated.

'The Public Accounts Committee seems to share our view that NHS England's obsession with 'saving' money fails spectacularly to take account of the human cost on the hundreds of dentists forced to wait for months before they could care for their patients or support their families.

'The PAC has exposed NHS England's outsourcing of back office functions to Capita where profits come first. This is a false economy, which has short-changed patients and taxpayers and undermines the NHS.'

A spokesperson for Capita said: 'Capita has apologised for unacceptable failings in relation to the initial delivery of this contract.

'We are now meeting the vast majority of key performance targets, and have put in place a new governance arrangement with NHS England to ensure improvement continues.'

1. Public Accounts Committee. Supporting Primary Care Services: NHS England's contract with Capita (25 July 2018). https://publications. parliament.uk/pa/cm201719/ cmselect/cmpubacc/698/69802.htm (accessed 13 August 2018). 